\title{
EFFECT OF INTERCROPPING AND NEIGHBOR SYSTEMS OF COTTON PLANTS AND OTHER SUMMER CROPS ON THE OCCURRANCE OF SOME COTTON PESTS AND ASSOCIATED NATURAL ENEMIES
}

\author{
M.M.A. Ibraheem ; A.A.A. Abd Allah and H.M.H. Al-Shannaf \\ Plant Protection Institute, Dokki, Giza, Egypt.
}

\section{ABSTRACT}

This study was conducted to evaluate the effect of intercropping and neighbor cotton plants with other summer plants on the occurrence levels of some cotton pests in Graia village at Zagazig, Sharkia Governorate during 2003 and 2004 seasons. The results show that Intercropping cotton with tomato or onion increased Aphis gossypii ( Glover) average numbers significantly on cotton plants. While with cucumber and pepper the average numbers were decreased in both 2003 and 2004 seasons. The average numbers of Tetranychus spp. increased in intercropping system of cotton with tomato or cucumber, while the contrast results was found with onion or pepper intercropping system in comparing with the solid cotton plants during 2003 and 2004 seasons. The all intercropping systems increased the population density of Thrips tabaci (Lind.) on cotton plants in comparable with solid plants in both of seasons. The influences of intercropping systems on Bemisia tabaci (Genn.) and Empoasca sp. were differed from season to another and from system to another.

With respect to the occurrence of associated natural enemies under intercropping systems, the highest population density of predators, Scymnus spp. and Orius spp. were recorded on cotton plants intercropped with tomato in both seasons. While, the highest number of predators ( Syrphus sp.,) Paederus alfierii, true spider mites, predator mite (Phytoseiulus sp.) and parasitoids, Encarsia sp. and Ertmocerus sp. were recorded on solid cotton plants compared to the intercropping systems in the two study seasons. The highest numbers of Chrysoperla carnea were detected on cotton plants intercropped with cucumber, whereas, the highest average number of Coccinella spp. recorded on cotton plants intercropped with onion in the first season and cotton plants intercropped with tomato in the second one.

As neighbor effect, the numbers of Empoasca sp. and T.tabaci was increased on cotton plants, while the numbers of A. gossypii, B. tabaci and Tetranychus spp. were decreased in both of seasons 2003 and 2004.

The neighbor of cotton plants by tomato, cucumber, onion or pepper was increased the numbers of predators (Chrysoperla carnea, Orius spp., Paederus alfierii) and parasitoid, Encarsia sp. on cotton plants; while the numbers of Coccinella spp. Scymnus spp., Syrphus spp., true spider mites and Ertmocerns sp. were decreased in both seasons.

Key words: Intercropping, neighbor systems, cotton plants, summer crops occurrence cotton pests, natural enemies 


\section{INTRODUCTION}

The cotton plants are infested with insects and animals pests throughout the different growth stages, i.e., A. gossypii; B.tabaci, Empoasca sp., T. tabaci and Tetramychus spp.; associated with predators (Coccinela sp., Chrysoperla carnea, Scyminus spp., Syrphus spp., Paederus alferii, Trus spidermites. Phytoseiulus sp. and Parasitoids (Encarsia sp. and Ertmocerns spp). ( Al-Shannaf, 1994 and Ibraheem, 2001).

Recently, many farming systems oriented to maximized the area income so, more than one crop are planted in the same area as intercropping systems that influenced the population densities of cotton pests and its associated natural enemies. Wu et al. (1991), Sharaf El-Din et al. (1993), Omar et al. (1994), Chakravarthy et al. (1997) and Al-Shannaf (2002).

This study new approach to evaluate the effect of intercropping and neighbor systems as mimic of natural farming systems on the occurrence of some cotton pests and associated natural enemies.

\section{MATERIALS AND METHODS}

Field experiments were carried out in Gria village, Zagazig, Sharkia Governorate, Egypt during 2003 and 2004 cotton growing seasons.

The experimental area was cultivated with the cotton variety Giza 85 .

\section{1-Intercropping systems}

Field experiments were carried out to study the effect of intercropping systems of tomato, Lycopersilcon esculentum; cucumber, Cucumis sativus; onion, Allium cepa L. or pepper, Capasicum fruitascens with cotton plants using one intercropping system, 1:1 ridge. on population density of some main cotton pests compared to cotton solid plants. The area of each treatment half feddan was divided into three replicates. All agricultural practices were carried out as Agric. Min. Recommendation in due time.

\section{2-Neighbor crop systems:}

The effect of neighbor crop systems of okra, Hibiscus esculentus L.; Eggplant, solanum melongena; Squash, cucurbita vito, Cowpea, Vigna sinensis Savi; Sesame, sesamum indicum L.; maize, Zea maize L.; mallow, Corchorus olitarius L., pepper, Capsicum friutascens and coriander, Coriandrum sativum L. in 1-2 Kerat of each plant species on the density of cotton pests and associated natural enemies field head of cotton which were $1 / 2$ feddan for each treatment; on the population.

After four weeks of cotton sowing date, weekly samples of 25 seedlings or $25^{\text {th }}$ leaves were investigated visually for each of cotton plants and different intercropped or neighbor plant species at random from different levels of plant canopy until harvest. The numbers of aphids as well as leafhoppers (nymphs and adults) and thrips (larvae and adults) were counted on the two surfaces of each leaf, while whitefly (larvae and pupae) and spider mite (moving individuals) were counted in an area of one inch ${ }^{2}$ on both of two leaves surfaces. 
The numbers of associated predators, (Coccinella spp., Chrysoperla carnea; Scyminus spp., Orius spp.; Syrphus spp., Paederus alfierii; true spider mites and Phytoseiulus sp.) and parasitoids (Encarsia sp. and Ertmocerus sp.) were recorded for all treatments.

The obtained resulted were statistically analyzed in according to Little and Hills (1975).

\section{RESULTS AND DISCUSSION}

\section{1-Effect of intercropping:}

Data in Table (1) clear that, the influence intercropping systems of tomato, cucumber, onion or pepper with cotton plants where they were influenced the occurrence of some cotton pests and associated natural enemies as follows:

\section{a-Cotton pests:}

\section{1-The cotton aphid, Aphis gossypii (Glover):}

Data in Table (1) show that, the cotton plants intercropped with tomato were infested by $A$. gossypii more than those solid plants with relatively highest numbers of 46.35 and 52.04; 34.09 and 38.61 individ. /leaf were recorded in both of 2003 and 2004 seasons, respectively, while the lowest numbers of 22.0 and 24.44 individ. /leaf harbored cotton plants intercropped with pepper in 2003 and 2004 seasons, respectively.

On the other hand, the mean numbers of $A$. gossypii on the cucumber, tomato and pepper plants intercropped with cotton were 29.0, 17.75; 17.85, 11.39 and 2.96; 3.26 individual /leaf in both of 2003 and 2004 seasons, respectively.

The onion plants intercropped with cotton were free from A. gossypii infestation allover these trials.

\section{2-The whitefly, Bemisia tabaci (Genn.):}

Data in Table (1) clear that, the cotton-cucumber intercropping system increased the population density of whitefly significantly recorded, 21.39 and 32.87 individual. inch 2 compared to 24.96 and 22.26 individ. /inch ${ }^{2}$ for solid cotton in both of 2003 and 2004 seasons, respectively. The intercropping systems of the onion or pepper with cotton plants decreased population density of whitefly significantly on intercropped cotton plant recorded $17.65,17.30$ and $12.3,17.22$ individ./inch ${ }^{2}$ on solid cotton plants compared to 24.96 and 22.26 individ. /inch ${ }^{2}$ in 2003 and 2004 seasons, respectively.

On the other side the relatively highest population density of whitefly were 35.54 and 96.19 individ. $/$ inch $^{2}$ recorded on cucumber plants followed by $22.74,17.96$ and 6.96, 16.17 individ. / inch $^{2}$ recorded on tomato and pepper in both of 2003 and 2004, seasons respectively.

\section{3-The leafhoppers, Empoasca spp.}

The present data in Table (4) show that, the intercropping was influenced, the occurrence of leaf happens significantly in compared with solid cotton plants. The highest population density were, $7.44,6.04,4.35$ and 2.30 individ./leaf recorded on cotton plants 
IBRAHEEM ET AL 
intercropped with cucumber, tomato, onion or pepper in the first season. As second season results, the numbers of 5.47,5.13, 4.44 and 4.35 individ./leaf were occurred on cotton plants intercropped with tomato, cucumber, pepper or onion, respectively.

In regarded to the population density of leafhopper insects on the plant species intercropped with cotton plants, the highest numbers of (5.62, 5.3, 4.01, 3.04 and 1.26, 1.47 individ. /leaf were recorded on cucumber, pepper and tomato in both 2003 and 2004 season, respectively.

\section{4-The cotton thrips, Thrips tabaci Lind:}

Data in Table (1) indicate that, the intercropping systems affected thrips numbers significantly recording 9.57, 10.5.7; 9.22, 9.17; 7.87, 8.17 and 6.44, 5.74 individ./leaf on cotton plants intercropped with onion, cucumber, tomato or pepper plants, respectively; in compared with 4.0 and 4.65 individ./leaf on solid cotton during 2003 and 2004 seasons, respectively.

On the other hand, the highest average numbers of 17,92 and 62,0 were recorded on onion plants followed by $8,75,24,42 ; 3.92,5.92$ and $3.42,2.5$ individ./leaf on cucumber, tomato and pepper plants during 2003 and 2004 seasons, respectively.

\section{5- Spider mite, Tetranychus spp.}

The results in Table (1) show that, the intercropping systems of cucumber or tomato with cotton plants increased the population density (moving stages) of spider mite,

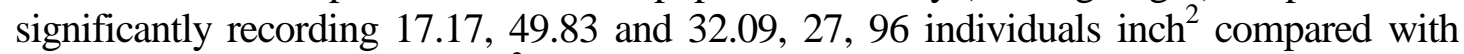
16.53 and 22.90 individ./inch ${ }^{2}$ on solid cotton plants during 2003 and 2004 seasons, respectively. But intercropping onion or pepper with cotton plants decreased population density of spider mite recording 14.26, 18.04 and 15.04,15.83 individ./inch ${ }^{2}$, respectively; in compared with 16.53 and 22.9 individ./inch ${ }^{2}$ on solid cotton plants during 2003 and 2004, respectively.

With respect to the effect of intercropping systems on population density of Tetranychus sp. on intercropped plant species the numbers of 52.27 and 37.89 individ./inch ${ }^{2}$ followed by $22.35,31.93$ and 10.26, 9.56 individ./inch $^{2}$ were recorded on tomato, cucumber, and pepper during 2003 and 2004, seasons respectively.

The present results found in agreement with those of Sharaf El-Din et al. (1993) and Chakravarthy et al. (1997), who found that, intercropping onion - cotton cultivated in ridges was the most suitable culture system for reducing the infestation of T. tabaci, A. gossypii and B. tabaci, on onion plants. Also, Al-Shannaf (2002) found that, intercropping roselle, sunflower, okra or guar with cotton using four intercropping systems caused a decreasing in population density of A. gossypii, (Tetranychus spp. while it's increased the population density of B.tabaci and Empoasca spp. compared with solid cotton plants.

\section{B- Effect of intercropping on natural enemies:}

Data in Table (2) indicated that, the intercropping of cotton plants with plant species, i.e., tomato, cucumber, onion or pepper. Concerning the effect of intercropping were influenced on the occurrence of Coccenella spp.; significantly where the highest 
IBRAHEEM ET AL 
average numbers of 2.66 and 3.01 individ./plant recorded on cotton plants intercropped with onion, whereas the relatively highest numbers of 1.64 and 1.76 individ./ plant as intercropped species occurred on tomato plants/ compared with 2.22 and 2.15 individ./ plant detected on solid cotton during 2003 and 2004 seasons, respectively. The lowest average numbers were $0.37,0.91$ and $0.0,0.0$ individ./ plant recorded on cotton and pepper as intercropping systems during 2003 and 2004 seasons, respectively.

With respect to the influence on the Chrysoperla carnea, the highest average numbers were 4.60, 3.48 and $2.93,3.01$ individ. /plant detected on cotton and cucumber in both of 2003 and 2004 seasons, compared with 2.74 and 2.27 individ./plant recorded on solid cotton, whereas the lowest averages were 1.15 and 1.27 recorded on cotton intercropped with pepper and cucumber during 2003 and 2004 seasons. But the lowest average numbers of 1.09 and 1.13 individ./plant were recorded on tomato as intercropped plants with cotton during 2003 and 2004 seasons.

Data in Table (2) show the highest average numbers of Scyminus spp. as 2.78 and 2.96 individ./plant recorded on cotton intercropped with tomato compared with 0.0 and 0.0 individ./ plant occurred on solid cotton, whereas the lowest average 2.01 and 1.97 individ. /plant on cotton intercropped with pepper plants during 2003 and 2004 seasons, respectively.

The highest numbers were recorded on cucumber plants as rites cropped plants were 1.12 and 1.27 individ./plant during the two study seasons, respectively. On the other hand the highest average numbers of Orius spp. were 3.26 and 4.02 individ /plant occurred on cotton intercropped with tomato in comparable with 0.0 and 0.0 insect/plant on solid cotton, whereas the lowest average numbers were 1.96 and 1.89 individ./plant recorded on cotton intercropped with pepper plants during 2003 and 2004 seasons, respectively.

On contrary, the highest average numbers true spider mites were 2.43 and 2.53 individ. /plant occurred with the solid cotton followed by 1.82 and 1.75 individ. /plant recorded on cotton intercropped with onion plants during 2003 and 2004, respectively. In case of the parasitoids, i.e. Encarsia sp. ranged 0.15-0.34 individ./plant on intercropped cotton compared with 2.0 -2.03 individ /plant on solid cotton, while Ertmocerus sp., ranged 0.13-0.35 individ / plant on intercropped cotton in comparable.

\section{II-Effect of neighbor on the occurrence of cotton pests and associated natural enemies a-Cotton pests on cotton plants :}

Data presented in Table (3) indicate that, the neighbor species plants (okra, eggplant, squash, cowpea, sesame, mallow, pepper and coriander) / with cotton plant as well as farming system significantly effected on population density of the cotton pests, i.e., A.gossypii, B. tabaci, Empoacsca spp., T.tabaci and Terranychus spp. on cotton plants during 2003 and 2004 seasons.

The obtained results revealed that, the highest population density of $A$. gossypii were 21.64 and 39.60 aphids/leaf occurred on cotton plants neighbor okra plant compared with 20.82 and 35.13 aphids/leaf recorded with the cotton solid (far from other plant species in cotton area) in both of 2003 and 2004 seasons respectively. On the other hand, 
IBRAHEEM ET AL 
the lowest population density of A. gossypii were 13.00 and 14.58 aphids/ leaf detected on cotton plant neighbor both of squash and sesame plants during 2003 and 2004, respectively.

The neighbor systems significantly influenced on the population density of $B$. tabaci on cotton plants during 2003 and 2004 seasons.

The highest average numbers of 30.0 and 30.61 individ / inch $^{2}$ were recorded on cotton plants neighbor cowpea compared with 16.26 and 16.61 individ. / inch ${ }^{2}$ recorded with pure cotton, whereas the lowest population density of 4.83 and 7.70 plants occurred on cotton leaves neighbor squash and okra plants during 2003 and 2004, respectively.

On the contrary, the influence of neighbor on the population density of both E. mpoasca $s p$. and T. tabaci in both seasons, resulted in clearly reducing in the occurrence of these pests on cotton plants neighbor of previous mentioned plant species compared with the highest population density of $9.35,9.04$ and $20.57,24.27$ individuals/ leaf recorded with pure area cotton for both insects during 2003 and 2004, respectively.

In case of Tetranychus spp., the highest population density of 34.17 and 55.83 moving individuals $/$ inch $^{2}$ were detected on cotton leaves neighbor eggplants compared with 21.61 and 32.91 individuals/inch ${ }^{2}$ on pure area cotton during 2003 and 2004 seasons, respectively. On the other hand, the lowest population density of 7.48 and 5.91

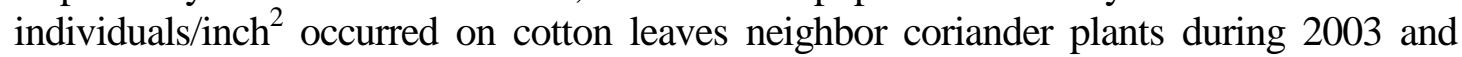
2004 seasons, respectively.

\section{b-Cotton pests on the other plant species:}

Data in Table (4) indicate that, the neighbor of plant species okra, egg plant, squash, cowpea, sesame, mallow, pepper and coriander to cotton plants were significantly influenced on the population density of cotton pests on these plant species in compared with pure area cotton in both of 2003 and 2004 seasons.

With respect to the population density of A. gossypii and T. tabaci the highest numbers were 20.09, 59,52 and 21.36, 2427 individuals/leaf recorded on okra plants compared with $14.17,35.13$ and 13.91, 23.64 individuals/leaf for pure area cotton, whereas the lowest average numbers of $1.09,0.26$ and $0.27,0.55$ individuals/leaf recorded on mallow and coriander during 2003 and 2004 seasons, respectively.

Concerning, the effect on B.tabaci and Tetranychus spp., the highest occurrence of these pests were 32.61, 72.91 individ./ inch $^{2}$ and 127.83, 149.22 individuals / inch $^{2}$ recorded on eggplant compared with $16.26,30.61$ and $21.61,32.91$ on pure area of cotton, while the lowest numbers of $0.91,0.04$ and $3.00,4.57$ were recorded with coriander plants during 2003 and 2004 seasons, respectively.

In regard to, the influence on Empoasca sp. the highest population densities were 12.04 and 12.00 individ./leaf occurred on cowpea compared with 9.35 and 8.04 individuals/leaf for pure area cotton, whereas the lowest averages numbers 0.36 and 0.27 individuals / leaf detected with coriander plants during 2003 and 2004 seasons, respectively.. 
IBRAHEEM ET AL 


\section{c-Effect of neighbor on occurrence of associated natural enemies in compared with cotton neighbor:}

The obtained results in Table (5) show that, the neighbor of some plant species (okra, eggplant, squash, cowpea, sesame and maize) to cotton plants was affected the population densities of associated natural enemies (predators and parasitoids) on plant species compared with cotton neighbor significantly in both of 2003 and 2004 seasons.

Concerning the Coccinella spp., the highest average numbers of 3.78, 3.89; 2.96, 3.15 and 2.78, 3.01 individ./ leaf were occurred on okra , eggplant and maize compared with 2.96 and 3.17 recorded with neighbor cotton plants during 2003 and 2004 seasons, respectively. On contrary, each of squash, cowpea and sesame were free from predator in both seasons.

With respect to, the Chrysoperla carnea, the highest population densities of 2.87 and 2.93 individ./leaf were occurred with squash compared to 3.04 and 3.27 recorded with neighbor cotton/plants, where as the lowest average numbers were 0.87 and 0.96 detected with cowpea during 2003 and 2004 seasons, respectively.

Data in Table (5) show that the highest average numbers of Scymenus spp., 4.67 and 5.15 individ./ leaf recorded to squash followed by $2.26,2.42$ and 1.26, 1.41 individ./leaf occurred on eggplant and okra compared with 1.39 and 1.52 individ./leaf recorded with neighbor cotton plants, while did not recorded this predator on both cowpea, sesame and maize during 2003 and 2004 , respectively.

On the other hand, the highest average of Paederus alfierii 1.96 and 2.07 individ. /leaf recorded with maize compared with 2.44 and 2.55 individuals /leaf detected with neighbor cotton whereas did not detect this predators on Okra, eggplant, cowpea and sesame during both of 2003 and 2004 respectively. On contrary data in Table (5) cleared that the few average numbers the other predators in compared with previous mentioned natural enemies.

In sides of parasitoids, sp. the numbers ranged 0.0-0.96 individ./plant on nigh bar plants in compared with $1.56-1.75$ individual/plant on neighbor cotton plant. The present results are agreement with those obtained by Wu et al. (1991) and Cui and Xia (1998) who reported that intercropping cotton plant with wheat and maize increase the average number of coccinellidae, chrysopidae and Orius minutus on cotton plants.

\section{REFERENCES}

Al-Shannaf. H.M.H. (1994): Ecological studies on certain cotton pests in Sharkia Governorarte . M.Sc. Thesis , Fac. Agric., Zagazig Universty.PP188

Al-Shannaf. H.M.H. (2002): Studies on some cotton pests. Ph. D. Thesis, Fac. of Agric., Zagazig University.

Chakravarthy, A.K.; G.B. Mallikarjuna and R. Prasad (1997): Intercropping in cotton, Gossypium hirsutum checks insect pests build-up. Insect Environmental, 2-4: 131-132. 
IBRAHEEM ET AL 
Cui, J.J. and J.Y. Xia (1998): Effect of early seasonal strain of Btransgenic cotton on population dynamics of main pests and their natural enemies. Acta Gossypii Sinica, 10 (5) 155-262 (c.f. R.A.E., 87 (9); 1181).

Ibrahem, M.M.A. (2001) studies on some piercing - sucking insect pests infesting cotton plants. Ph.D. Thesis, Fac. Agric, Zagazig University Pag, (49-53).

Little T.M. and F. J. Hills (1975): Statistical Methods in Agricultural Research. Available from U.C.D. Bock Store, University of California, Davis: 241 pp.

Omar, H.I.H.; M.F. Haydar and A.E.M. Sorady (1994): Effect of sowing date of intercropping cowpea with cotton on infestation with some major pests. Egypt. J. Agric. Res., 72 (3): 691-697.

Sharaf El-Din , A.A.A.; I.I. Tsmail, M.A. Ali and M.Y. Hashem (1993): Effect of intercropping system and planting methods on the population pests. Bull. Entomal. Soc., Egypt, $71139-152$.

Wu,G.; Z. Chen; M.JI; S.Dong; H.Li; J. An and J. Shi (1991): Influence of intercropping corn in cotton fields on natural enemy populations and its effect of pests control in southern shaanti. J. Chinese Journal of Biological Control, 7 (3) : $101-104$. 
تأثير التحميل والتجاور ببعض الأنواع النباتية مع نبات القطن على مستوي

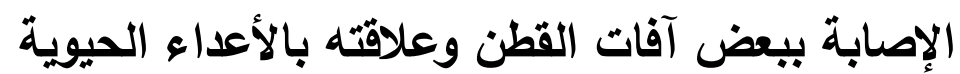

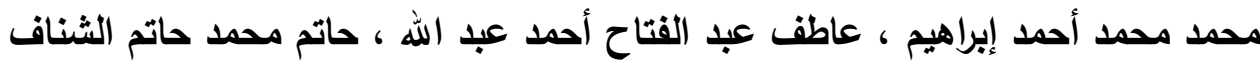

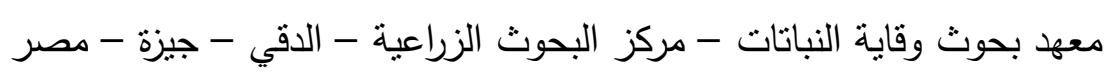

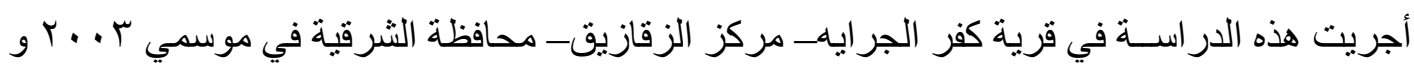

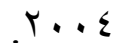

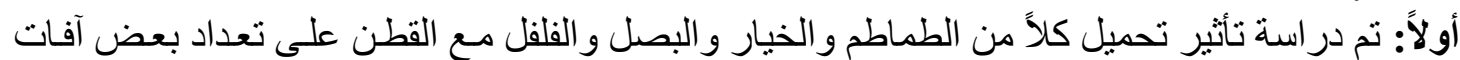

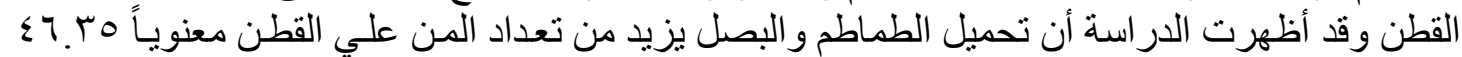

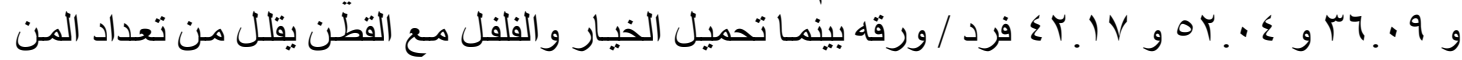

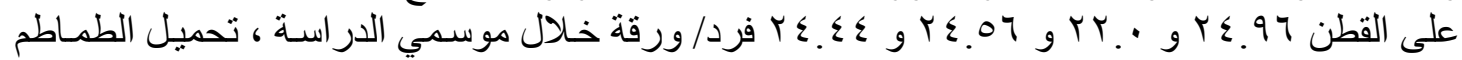

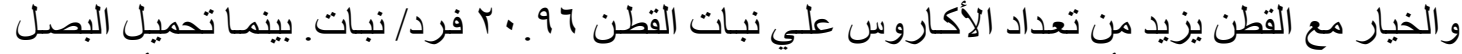

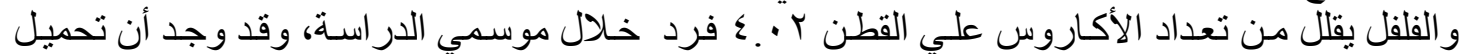

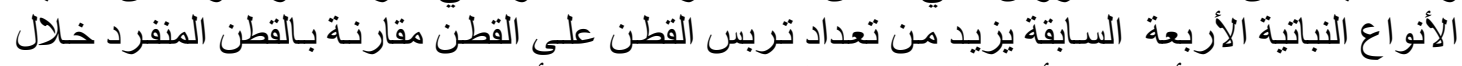

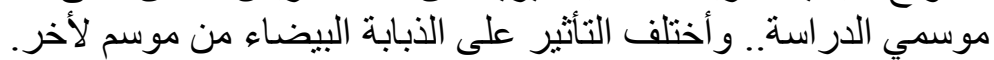

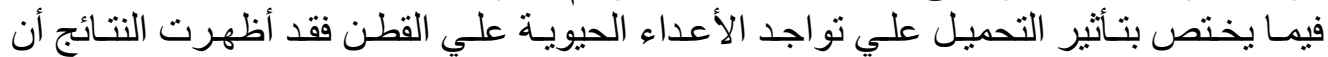

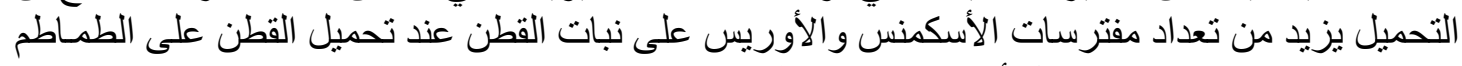

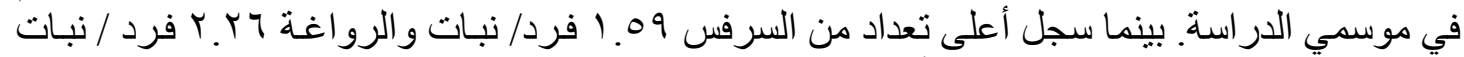

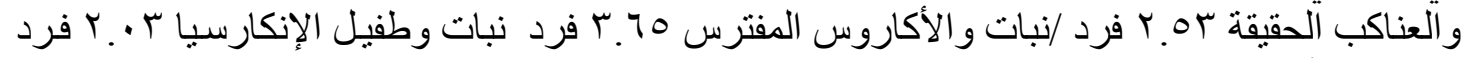

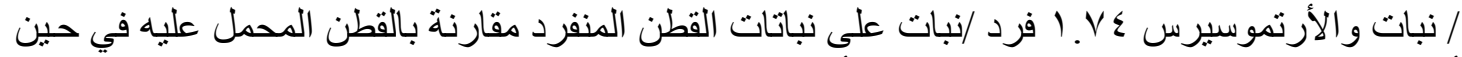

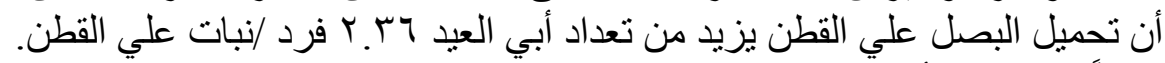

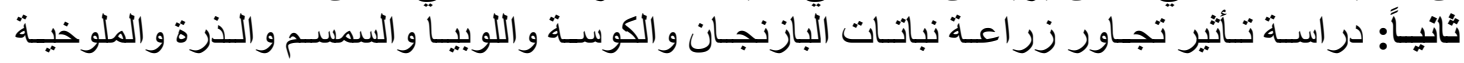

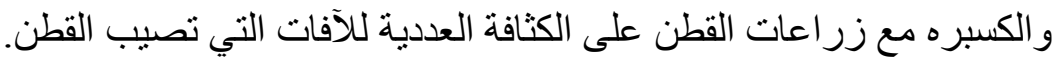

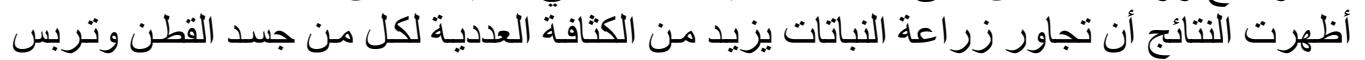

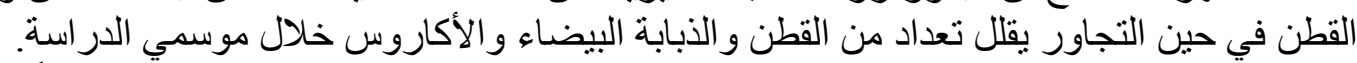

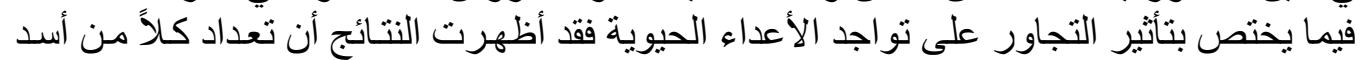

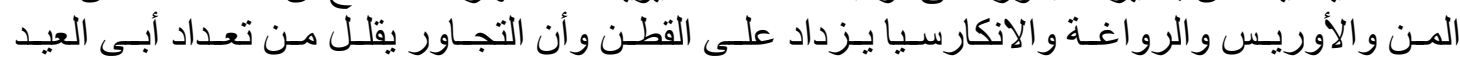

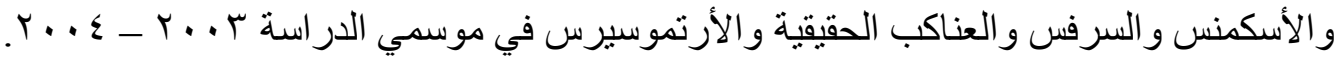

